\title{
Klucel $^{\mathrm{TM}}$ EF and ELF polymers for immediate-release oral dosage forms prepared by melt extrusion technology
}

\author{
Noorullah Naqvi Mohammed, ${ }^{1}$ Soumyajit Majumdar, ${ }^{2,4}$ Abhilasha Singh, ${ }^{2}$ Weibin Deng, ${ }^{2}$ Narasimha S. Murthy, ${ }^{2,5}$ \\ Elanor Pinto, ${ }^{3}$ Divya Tewari, ${ }^{3}$ Thomas Durig, ${ }^{3}$ and Michael A. Repka ${ }^{2,4,6}$
}

Received 25 April 2012; accepted 26 July 2012; published online 8 September 2012

\begin{abstract}
The objective of this research work was to evaluate Klucel ${ }^{\mathrm{TM}}$ hydroxypropylcellulose (HPC) EF and ELF polymers, for solubility enhancement as well as to address some of the disadvantages associated with solid dispersions. Ketoprofen (KPR), a Biopharmaceutics Classification System class II drug with poor solubility, was utilized as a model compound. Preliminary thermal studies were performed to confirm formation of a solid solution/dispersion of KPR in HPC matrix and also to establish processing conditions for hot-melt extrusion. Extrudates pelletized and filled into capsules exhibited a carrier-dependent release with ELF polymer exhibiting a faster release. Tablets compressed from milled extrudates exhibited rapid release owing to the increased surface area of the milled extrudate. Addition of mannitol (MNT) further enhanced the release by forming micro-pores and increasing the porosity of the extrudates. An optimized tablet formulation constituting KPR, MNT, and ELF in a 1:1:1 ratio exhibited $90 \%$ release in $15 \mathrm{~min}$ similar to a commercial capsule formulation. HPC polymers are non-ionic hydrophilic polymers that undergo polymer-chain-length-dependent solubilization and can be used to enhance solubility or dissolution rate of poorly soluble drugs. Dissolution/release rate could be tailored for rapid-release applications by selecting a suitable HPC polymer and altering the final dosage form. The release obtained from pellets was carrier-dependent and not drug-dependent, and hence, such a system can be effectively utilized to address solubility or precipitation issues with poorly soluble drugs in the gastrointestinal environment.
\end{abstract}

KEY WORDS: hot-melt extrusion; Klucel ${ }^{\mathrm{TM}}$ EF/ELF; solid solutions/dispersions; solubility enhancement; thermal miscibility evaluation.

\section{INTRODUCTION}

Solubility enhancement of poorly soluble drugs is an extensively researched area in the current pharmaceutical industry. With over $40 \%$ of new chemical entities having higher molecular weight and highly lipophilic in nature, pharmaceutical research is being directed toward better solubilization techniques to counter this challenge. Technologies such as solid dispersions have proven viable and been used extensively due to inherent advantages over other technologies (1). Techniques such as solvent evaporation (2), fusion method $(3,4)$, complexation, spray-drying (5), and hotmelt extrusion $(6,7)$ have been utilized to form solid dispersions, with spray-drying and hot-melt extrusion being the most widely utilized techniques (8). The processing steps involved in manu-

\footnotetext{
${ }^{1}$ Pharmaceutics International Inc., Hunt Valley, MD, USA.

${ }^{2}$ Department of Pharmaceutics, School of Pharmacy, The University of Mississippi, Oxford, Mississippi 38677-1848, USA.

${ }^{3}$ Ashland Research Center, Ashland Speciality Ingredients, 500 Hercules Rd., Wilmington, Delaware 19808, USA.

${ }^{4}$ Pii Center for Pharmaceutical Technology, The University of Mississippi, Oxford, Mississippi 38677, USA.

${ }^{5}$ Research Institute of Pharmaceutical Sciences, The University of Mississippi, Oxford, Mississippi 38677, USA.

${ }^{6}$ To whom correspondence should be addressed. (e-mail: marepka@olemiss.edu)
}

facturing solid dispersions might induce a physico-chemical transformation, and hence, stability assessment is of pivotal importance. Conversion to a high-energy amorphous form, being one of them, can also impart enhancement in solubility and hence bioavailability $(9,10)$. However, such high energy forms tend to recrystallize or precipitate out from their supersaturated solutions. Recrystallization and precipitation in these polymers or in the gastrointestinal tract can be controlled by use of crystallization inhibitors (11) or modifying the release to prevent supersaturation, while maintaining a concentration that would result in bioavailability enhancement $(12,13)$.

Hot-melt extrusion (HME) is a versatile processing technology that can be used for solubility enhancement, granulation, and as a physico-chemical stability imparting technology (14). Being a non-solvent process, HME has significant utility in the manufacture of solid dispersions and solid solutions. The intense mixing and shearing distributes the drug uniformly in a polymer matrix and depending upon the drug and polymer interactions, forms a solid solution or a solid dispersion (15). The extrudates can be further processed into pellets as multi-particulate systems, films, or into tablets by milling and addition of tabletting excipients (16). Many polymers have been evaluated for use in HME including hydroxypropylcellulose (HPC) (17), polyvinyl pyrrolidone (18), polyethylene oxide (19), and sugars such as isomalt (20), erythritol (21), and mannitol (22). Being a process that is performed at high temperatures, the polymers and the drug have 
to meet the requirement of being thermoplastic, stable, and able to withstand the shear being exerted by the screws.

Klucel $^{\mathrm{TM}}$ HPC polymers have been used previously to control drug release from hot-melt-extruded films (23) and as a granulation binder (24). HPC polymers are non-ionic polymers that release the drug by a mechanism of swelling and erosion. Work done in our lab earlier reported that rate of solubilization of HPC is dependent upon polymer molecular weight (17). Klucel ${ }^{\mathrm{TM}}$ hydroxypropylcellulose EF and ELF have an approximate molecular weight of 80,000 and $60,000 \mathrm{Da}$, respectively, and hence undergo a faster erosion process, thus aiding in release of poorly soluble drugs dispersed or dissolved in the polymer matrix (25). Being nonionic, $\mathrm{pH}$-independent release can be achieved from matrices manufactured from these polymers. We have evaluated immediate as well as rapid-release applications of Klucel polymers for solubility enhancement of poorly soluble drugs. Lower molecular grades of HPC, EF and ELF, were utilized to increase the solubility of a poorly soluble drug in a solid dispersion/solution. HME was utilized to intimately mix the components into a homogenous matrix. Ketoprofen (KPR) is a non-steroidal anti-inflammatory drug commonly used in treatment of pain and inflammation. Being a Biopharmaceutics Classification System Class II drug, dissolution is the ratelimiting step for absorption of orally administered KPR and hence was utilized as a model compound (26). Various techniques to increase solubilization have been explored including formulation of solid lipid nanoparticles using waxes and lecithin (27), dispersing in pellets using macrogols (28), hot-melt extrusion coupled with a cyclodextrin (29), self-emulsifying drug delivery systems (30), and lyophilization (31,32). Most of these techniques are multiple-batch processes that might also involve the use of organic solvents. Further processing might thus be required to manufacture a final dosage form that can be administered to a patient.

In the current research, preliminary screening studies were performed to evaluate HME feasibility utilizing DSC, thermogravimetric analysis (TGA) and hot-stage microscopy (33). The process was optimized and extrudates evaluated for in vitro release, crystallinity, and surface morphology. Extrudates were prepared into pellets, to be directly filled into capsules or milled to be compressed into tablets. The extrusion process converted crystalline KPR to an amorphous form, dispersing the same in a hydrophilic HPC matrix that resulted in increased dissolution rate. We have also made an attempt to explain dissolution mechanisms that play a significant role in solubility enhancement. HME also imparted physical properties to extruded systems that contributed toward better tabletting properties. Amorphous forms tend to recrystallize on storage, but Klucel ${ }^{\mathrm{TM}}$ polymers were able to maintain the drug in an amorphous form in the extrudates when stored at $40^{\circ} \mathrm{C} / 75 \% \mathrm{RH}$ for a period of 6 months.

\section{MATERIALS}

Ketoprofen USP was purchased from Letco Medical (1316 Commerce Dr. NW, Decatur, AL, 35601); Klucel ${ }^{\mathrm{TM}}$ hydroxypropylcellulose EF and ELF polymers (HPC) were obtained as gift samples from Ashland Aqualon Functional Ingredients (Wilmington, DE); Pearlitol ${ }^{\circledR}$ (mannitol (MNT)) was obtained as a gift sample from Roquette (1417 Exchange
Street, P.O. Box 6647, Keokuk, IA 52632). AcDiSol® and Avicel® 200 were received from FMC Biopolymers (1735 Market Street, Philadelphia, PA 19103); Aerosil@ was received from Evonik Degussa Corporation (379 Interpace Parkway, Parsippany, NJ 07054). Magnesium stearate was purchased from Mallinckrodt. The chemicals used were of analytical grade and obtained either from Fisher Scientific or Spectrum Chemicals

\section{METHODS}

\section{Thermal Characterization}

\section{Differential Scanning Calorimetry}

Polymer-drug miscibility studies were performed on binary mixtures of polymers Klucel ${ }^{\mathrm{TM}}$ ELF with KPR at increasing concentrations ranging from $10 \%$ to $90 \%$. A Perkin Elmer Hyper Differential Scanning Calorimeter (DSC) (Perkin Elmer Life and Analytical Sciences, 710 Bridgeport Ave., Connecticut, USA) was used to analyze the samples. Thermograms were generated by analyzing $2-3 \mathrm{mg}$ of the sample in an aluminum pan and heating it from $20^{\circ} \mathrm{C}$ to $200^{\circ} \mathrm{C}$ at a linear heating rate of $10^{\circ} \mathrm{C} / \mathrm{min}$. Endothermic onset and peak temperatures at melting were calculated from the software. Pyris manager software was used to analyze the data generated. Extruded systems were also studied similarly to evaluate crystallinity.

Modulated DSC (mDSC) studies were performed on Thermal Analytics Q1000 mDSC instrument to detect glass transition temperature of amorphous systems. Extrudates were evaluated for any recrystallization that might have occurred at the end of storage time points. The samples were heated in hermetically sealed aluminum pans from $-30^{\circ}$ to $170^{\circ} \mathrm{C}$ with a $1^{\circ} \mathrm{C} / \mathrm{min}$ modulation. Ramp rate was set to $3^{\circ} \mathrm{C} / \mathrm{min}$. The data were analyzed utilizing TA Universal Analysis software and glass transition $(\mathrm{Tg})$ temperature calculated by taking the midpoint of tangents drawn.

\section{Thermogravimetric Analysis}

A Perkin Elmer Pyris 1 TGA running Pyris manager software (PerkinElmer Life and Analytical Sciences, 719 Bridgeport Ave., Connecticut, USA) was used to perform thermogravimetric analysis of samples. Drug and excipients were evaluated for thermal stability at high temperatures. Three to four milligrams of the sample was weighed and heated from $25^{\circ} \mathrm{C}$ to $200^{\circ} \mathrm{C}$ at $10^{\circ} \mathrm{C} / \mathrm{min}$ heating rate under an atmosphere of nitrogen.

\section{Hot-Stage Microscopy}

Drug and excipient blends as per Table I were evaluated for miscibility using a hot-stage microscope and observed under polarized light for changes in crystallinity. A small amount of sample was spread on a glass slide and inserted into a hot-stage setup. Samples were heated at a constant heating rate of $10^{\circ} \mathrm{C} / \mathrm{min}$ from $25^{\circ} \mathrm{C}$ to $200^{\circ} \mathrm{C}$ and visually observed. Images were taken continuously at different steps of transformation using a digital camera. 
Table I. Formulation Composition of HME Pellets

\begin{tabular}{|c|c|c|c|c|}
\hline Formulations & Ketoprofen & KlucelTM ELF & Klucel $^{\mathrm{TM}} \mathrm{EF}$ & Mannitol \\
\hline H 1 & 33 & - & 66 & - \\
\hline H 2 & 33 & - & 33 & 33 \\
\hline H 3 & 33 & 66 & - & - \\
\hline $\mathrm{H} 4$ & 33 & 33 & - & 33 \\
\hline H 5 & 25 & 75 & - & - \\
\hline H 6 & 25 & 37.5 & - & 37.5 \\
\hline H 7 & 45 & 55 & - & - \\
\hline H 8 & 45 & 27.5 & - & 27.5 \\
\hline
\end{tabular}

\section{HPLC METHOD}

All the samples were analyzed on a Waters HPLC, and Empower software was used to analyze the data. The high-performance liquid chromatography (HPLC) consisted of a Water 600 binary pump, Waters 2489 UV/ detector, and Waters 717plus autosampler (Waters Technologies Corporation, 34 Maple St., Milford, MA 0157). A Waters Symmetry shield C18, $250 \times 4.6 \mathrm{~mm}, 5 \mu \mathrm{m}$ particle size reverse-phase column was used as a stationary phase, and the mobile phase constituted 55:45 (\%v/v) acetonitrile/20 mMol phosphate buffer at $\mathrm{pH} 4$ (19). The UV detector was set at $256 \mathrm{~nm}$ wavelength. For assay determination, accurately weighed samples were dissolved in $20 \mathrm{ml}$ of methanol, filtered, and then injected at a $20 \mu \mathrm{l}$ injection volume. Assay for tablets was performed by disintegrating the tablets in water and extracting the drug in methanol prior to being injected on the HPLC. Six replicates were used for all the assay studies. Samples from dissolution studies were filtered and injected at a $20 \mu \mathrm{l}$ injection volume.

\section{FORMULATION}

\section{Formulation Composition and HME Processing}

Two HPC polymers, Klucel ${ }^{\mathrm{TM}} \mathrm{EF}(\mathrm{EF})$ and Klucel ${ }^{\mathrm{TM}}$ ELF (ELF), were used at different drug concentration levels to evaluate their effect on solubility enhancement of KPR. Polymers and drug as per Table I were mixed in a V-cone blender (Maxiblend ${ }^{\mathrm{TM}}$, GlobePharma) at $25 \mathrm{rpm}$ for $10 \mathrm{~min}$ and samples analyzed for drug content and blend uniformity. The blended material was extruded on a 16 mm Prism Eurolab, ThermoFisher Scientific Co, rotating twin screw extruder utilizing a round-shaped die to yield extrudate rods. The temperature of the barrel was maintained at $100^{\circ} \mathrm{C}$ to $140^{\circ} \mathrm{C}$, and screw speeds of 50 or $70 \mathrm{rpm}$ were utilized. The extruded rods were pelletized to yield 1-mm pellets utilizing a pelletizer (Type L-0019482, Thermoscientific, Stone, UK). They were stored in nitrogen-filled plastic bags in a refrigerator until further evaluation. The pellets were evaluated for post-extrusion content using HPLC method. The pellets were filled in a size zero capsule to yield $50 \mathrm{mg}$ drug load or milled for tabletting.

\section{Tabletting}

The extruded material was rendered brittle by freezing in a refrigerator and milled in a Fitzpatrick ${ }^{\circledR}$ Mill (The Fitzpatrick Company, 832 Industrial Drive, Illinois, USA), hammers-forward configuration for $5 \mathrm{~min}$. The speed was maintained at $5,000 \mathrm{rpm}$, and sieve size corresponding to USP Sieve\# 18 was used. The tablet blends were prepared as per Table II. The 25and 50-mg strength tablets were compressed on a Mendelco MTP1 tabletting machine using an 8 and $11 \mathrm{~mm}$ biconcave punch, respectively. Tablet strengths $25 \mathrm{~T}$ and $50 \mathrm{~T}$ represent 25 and $50 \mathrm{mg}$, respectively.

\section{Evaluation of Extruded System-Pellets and Tablets}

\section{Microscopy Studies}

Scanning electron microscope (SEM) was used to study surface morphology of extruded pellets. Samples exposed to dissolution media were also evaluated after $1 \mathrm{~min}$, to study morphological changes post-dissolution. Samples were sputter-coated with gold using a Hummer® 6.2 sputtering system (Anatech LTD, Springfield, VA) in a high vacuum evaporator. A JEOL JSM-5600 scanning electron microscope operating at an accelerating voltage of $10 \mathrm{kV}$ was used for imaging. Samples were mounted on adhesive carbon pads placed on aluminum stubs prior to sputter coating.

\section{In Vitro Release Studies}

Extrudates equivalent to $50 \mathrm{mg}$ KPR were filled in capsules and in vitro release studies performed on a USP type I dissolution apparatus. Dissolution media constituting $900 \mathrm{~mL}$ of pH 6.8 phosphate buffer with $1 \%$ Tween $® 80$ added and maintained at $37^{\circ} \mathrm{C}$ was utilized. Paddle speed was set at $50 \mathrm{rpm}$. Samples were collected at every $0.25,0.5,0.75,1$, $1.5,2,3,4$, and $5 \mathrm{~h}$, filtered and then analyzed using an HPLC. An equal amount of fresh dissolution media was added back to the dissolution vessel at each time point. Release profiles were plotted for percent release to time. The dissolution profiles were compared utilizing model-independent, $f_{2}$ similarity factor values. Tablets formulated from extrudate material

Table II. Formulations Composition-Tablets Manufactured from HME Matrices

\begin{tabular}{|c|c|c|}
\hline Excipients $(\% w / w)$ & $\mathrm{H} 1-25 \mathrm{~T}$ & $\mathrm{H} 3-25 \mathrm{~T}$ \\
\hline Ketoprofen & 12.5 & 12.5 \\
\hline Klucel $^{\mathrm{TM}} \circledR^{\circledR} \mathrm{EF} / \mathrm{ELF}$ & $25(\mathrm{EF})$ & 25 (ELF) \\
\hline Avicel@ 200 & 59.5 & 59.5 \\
\hline Aerosil® & 0.5 & 0.5 \\
\hline AcDisol $®$ & 2 & 2 \\
\hline \multirow[t]{2}{*}{ Magnesium stearate } & 0.5 & 0.5 \\
\hline & $\mathrm{H} 2-25 \mathrm{~T}$ & $\mathrm{H} 4-25 \mathrm{~T} / 50 \mathrm{~T}$ \\
\hline Ketoprofen & 12.5 & 12.5 \\
\hline Klucel $^{\mathrm{TM}} \AA^{\circledR} \mathrm{EF} / \mathrm{ELF}$ & $12.5(\mathrm{EF})$ & $12.5(\mathrm{ELF})$ \\
\hline Mannitol & 12.5 & 12.5 \\
\hline Avicel $® 200$ & 59.5 & 59.5 \\
\hline Aerosil® & 0.5 & 0.5 \\
\hline AcDisol® & 2 & 2 \\
\hline Magnesium stearate & 0.5 & 0.5 \\
\hline
\end{tabular}


were tested similarly. In addition, statistical analysis was performed using ANOVA to compare the profiles.

\section{Powder X-ray Diffraction}

Powder X-ray diffraction (XRD) studies were performed on a D-8 Advance X-ray diffractometer (Bruker AXS) equipped with a SolX detector and running DiffracPlus ${ }^{\circledR}$ software. The generator voltage and current were set to $40 \mathrm{KV}$ and $30 \mathrm{~mA}$, respectively. The samples were scanned from $10^{\circ}$ to $40^{\circ}, 2 \theta$ values at $0.05^{\circ} \mathrm{ramp}$ and $3 \mathrm{~s} / \mathrm{step}$.

\section{Tablet Characterization}

Standard characterization tests were performed on tablets manufactured from extruded material. The thickness and diameter of the tablets was measured using a micrometer. Disintegration testing was performed on a Dr. Schleuniger Pharmatron USP (Schleuniger Pharmatron, Inc., 1 Sundial Ave., Manchester, NH 03103) disintegration apparatus. Friability testing was performed in a friabilator (Roche friabilator). A VarianVK200 (Agilent technologies, 13000 Weston Pkwy, Cary, NC, 27522) hardness tester was used to test the hardness of tablets. Six replicates were tested. Tensile strength was calculated from hardness values utilizing the following equation. $F$ is the force measured at tablet failure, $\mathrm{d}$ and $\mathrm{h}$ are the diameter and thickness of the tablet, respectively.

$$
T=\frac{2 F}{\pi d h}
$$

\section{Compaction Profiles}

Compaction profiles were generated for extruded and unextruded KPR formulations as per their definitions (34). A hydraulic Carver press (Fred Carver, Menomonee, WI) was used to compress tablets at different compaction pressures ranging from 50 to $500 \mathrm{MPa}$ using an $8-\mathrm{mm}$ punch. Tablets were tested for hardness and the tensile strength calculated. True density measurements of the tabletting blends were performed using a Micromeritics helium pycnometer (AccuPyc II 1340, 4356 Communications Dr., Norcross, Georgia 30093). Porosity measurements were made by calculating the true density of the tablets and utilizing it to calculate the percent solid fraction $(S)$ in the tablet. The percent porosity $(\varepsilon)$ was calculated using the following equation:

$$
\varepsilon=(1-S) \times 100
$$

Tabletability is represented by a plot of tensile strength versus compaction pressure, Compactibility by a plot of tensile strength versus porosity, and Compressibility by a plot of porosity versus compaction pressure (35).

\section{Texture Analyzer}

TA-XT Plus Texture Analyzer (Texture Technologies Corp., Scarsdale, New York) was used to calculate the hardness, work of failure, and percent change in diameter at tablet failure. A TA- 8 ball probe was used to exert diametrical force on a vertically placed tablet. The test probe travelled at $2 \mathrm{~mm} / \mathrm{s}$ until the tablet surface was detected at $0.05 \mathrm{~N}$, after which the probe travelled to a $3-\mathrm{mm}$ distance. A $10-\mathrm{kg}$ load cell was used to register the force exerted till the point of tablet breaking.

\section{Stability Testing}

Samples were stored in closed glass vials and evaluated for physical and chemical stability for a period of 6 months utilizing DSC, mDSC, XRD, and chemical assay. Refrigerated $25^{\circ} \mathrm{C} / 60 \% \mathrm{RH}$ and $40^{\circ} \mathrm{C} / 75 \% \mathrm{RH}$ conditions were utilized. The studies were performed utilizing six replicates. In vitro release studies were performed on tablets stored at different stability conditions. The release profiles were compared based on calculated similarity factor values.

\section{RESULTS AND DISCUSSION}

\section{Thermal Characterization}

A hot-stage microscope was used to replicate temperatures the material would be exposed to inside an extruder while polarized light microscope (PLM) was used to observe the changes in the material. PLM aids the differentiation of a crystalline form from a glassy/amorphous form and was hence utilized in this study $(21,36)$. Crystalline KPR started to melt at around $97^{\circ} \mathrm{C}$ and converted to a molten form. HPC softened around $130^{\circ} \mathrm{C}$, and on melting completely, was found to be miscible with KPR (Fig. 1a). Similar transformations were observed in $\mathrm{H} 2$ formulation for HPC, KPR, and MNT. However, MNT which melted at $170^{\circ} \mathrm{C}$ started to recrystallize back at $70^{\circ} \mathrm{C}$ (Fig. 1b). Extrusion conditions were maintained so as to maintain MNT in a crystalline state; DSC results confirmed the same. The hot-stage microscope confirmed the formation of a miscible amorphous system of KPR-EF mixtures (37). KPR-ELF systems exhibited similar results and hence have not been presented here.

\section{Miscibility Studies}

At all the concentrations evaluated, KPR and HPC were found to be miscible with each other. The endothermic melting peak of KPR was comparatively lower to that of pure KPR till a $60 \%$ drug loading. This suggested partial solubilization of KPR and HPC during the heating step (Fig. 2a-b; 38,39). This decrease in melting point temperature can also be attributed to drug-polymer interactions drop (40). KPR melting peak was not observed in the second reheating step which confirmed formation of an amorphous KPR. H1-H4 physical mixtures as well as pure KPR were similarly evaluated on an mDSC. Pure KPR exhibited a $\mathrm{Tg}$ around $0.85^{\circ} \mathrm{C}$, and $\mathrm{HPC}$ has been reported to have a $\mathrm{Tg}$ in between $-25^{\circ} \mathrm{C}$ to $0^{\circ} \mathrm{C}$, which is dependent upon percent humidity (24). Extruded formulations exhibited a single $\mathrm{Tg}$ in the range of $2^{\circ} \mathrm{C}$ to $4^{\circ} \mathrm{C}$, suggesting this to be of a miscible single-phase solid solution of KPR and HPC (37). DSC studies have been employed to characterize miscibility of amorphous systems extensively (41). An immiscible amorphous system would exhibit two Tgs whereas a miscible system exhibits a single Tg on a DSC run. Based on results obtained from 
thermal studies, it was confirmed that KPR forms a solid solution with HPC polymers, and they were found to be miscible with each other. HME processing temperatures were set as per data obtained from DSC and hot-stage studies.

\section{Hot-Melt Extrusion Process}

Kluce ${ }^{\mathrm{TM}}$ polymers, owing to their thermoplastic and thermostable nature, have been utilized to form HME matrices earlier by Repka and group $(17,23)$. HPC polymers are semicrystalline polymers that soften over a range of temperatures from $100^{\circ} \mathrm{C}$ to $140^{\circ} \mathrm{C}$ and have been extruded at $120^{\circ} \mathrm{C}$ to $170^{\circ}$ C $(42,43)$. Earlier studies performed on HPC HF, a higher molecular weight grade of HPC, report the advantages of using plasticizers and plasticizing effect of drugs (43). KPR which melts at $97^{\circ} \mathrm{C}$ has been known to provide plasticization effect for the melt (19). A similar effect was observed with our formulations, and hence extrusion could be carried out at a lower temperature and higher screw speeds. Lower molecular weight polymers such as Klucel ${ }^{\mathrm{TM}} \mathrm{EF}$ and ELF, due to smaller chains, have comparatively lower viscosity and hence exerted lesser torque. The extrusion temperature could be lowered significantly $\left(100-120^{\circ} \mathrm{C}\right)$ for ELF polymer formulations when the drug loading was $45 \%$ due to the plasticizing property of the drug beyond its melting point.

HME conditions including barrel temperature and screw speeds were optimized for maximum yield and were set according to observations made from thermal studies. A temperature setting of $100^{\circ} \mathrm{C}-140^{\circ} \mathrm{C}$ and $75 \mathrm{rpm}$ screw speed resulted in formulations with highest yield. KPR on melting exhibits a tacky nature and cannot be extruded on its own without a matrix. Crowley et al. tried to extrude KPR-polyethylene oxide blends but could not extrude it above $30 \%$ level due to the tacky nature (19). In our experiments, HPC provided a matrix for the drug and aided formation of solid extrudate rods that could be pelletized. HME performed on H7-H8 (45\% drug load) exhibited slightly similar behavior as observed by Crowley et al. but could a

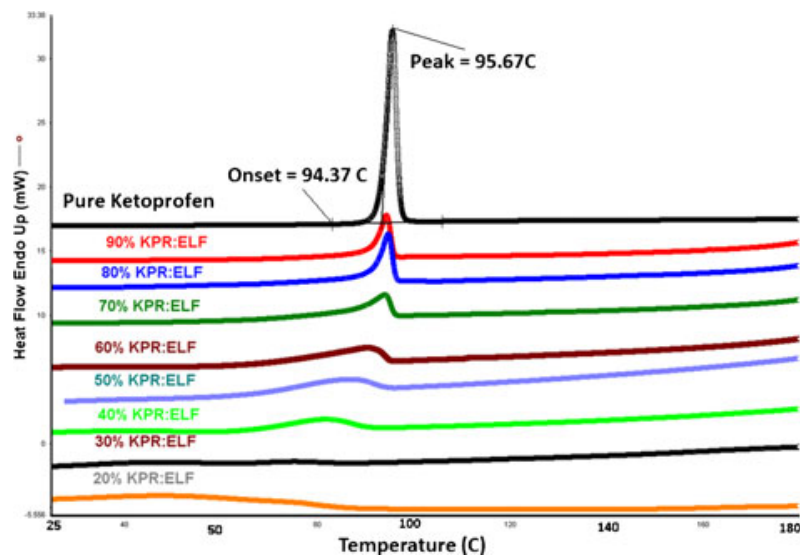

b

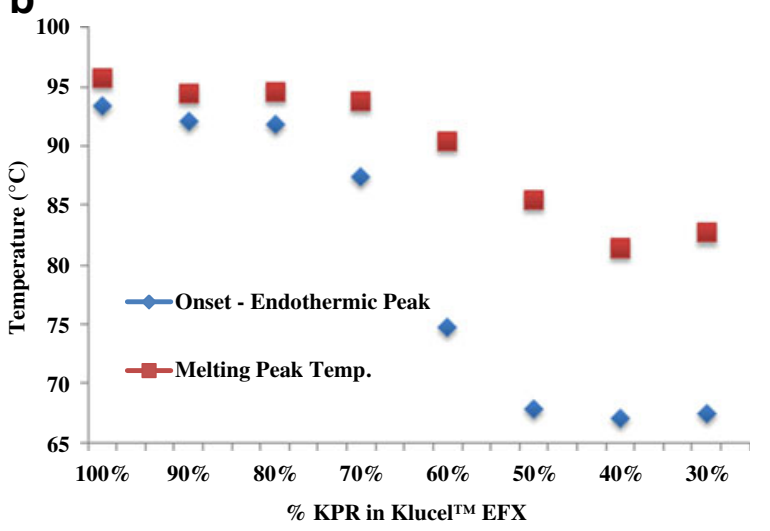

Fig. 2. a DSC thermograms first-heating step. b Polymer drug miscibility studies

still be extruded at a lower temperature of $100^{\circ} \mathrm{C}$ to $120^{\circ} \mathrm{C}$. Addition of mannitol significantly aided the extrusion and pelletizing process in these formulations. The extrusion conditions

a

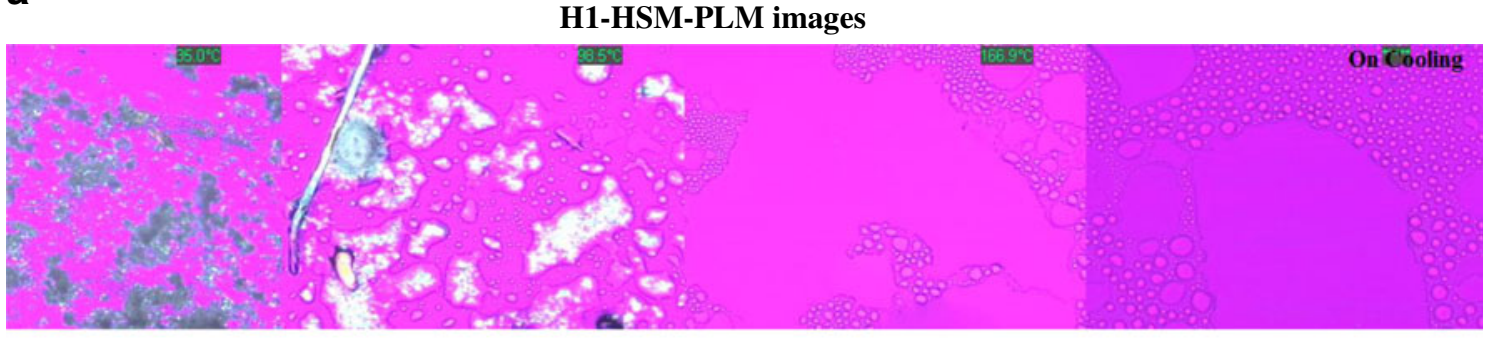

b

H2-HSM -PLM images

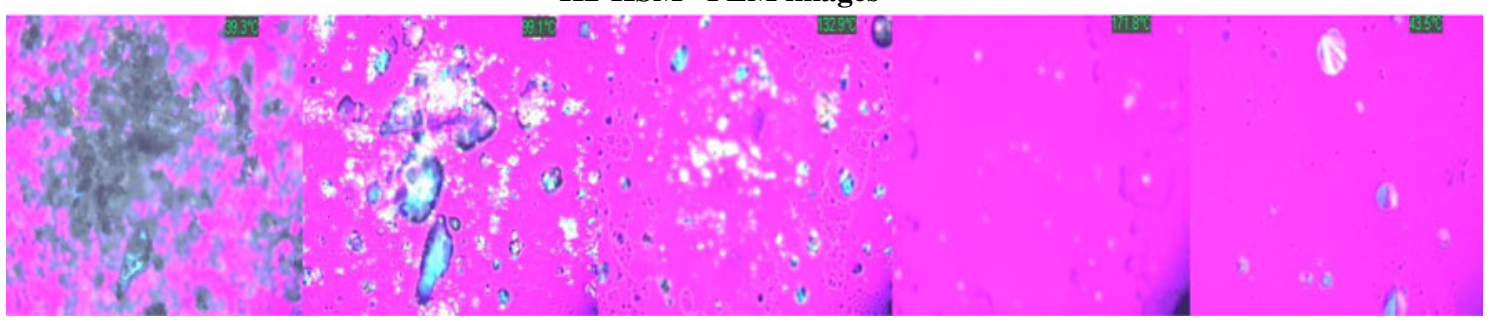

Fig. 1. HSM-PLM images of (a) H1 and (b) H2 formulations 

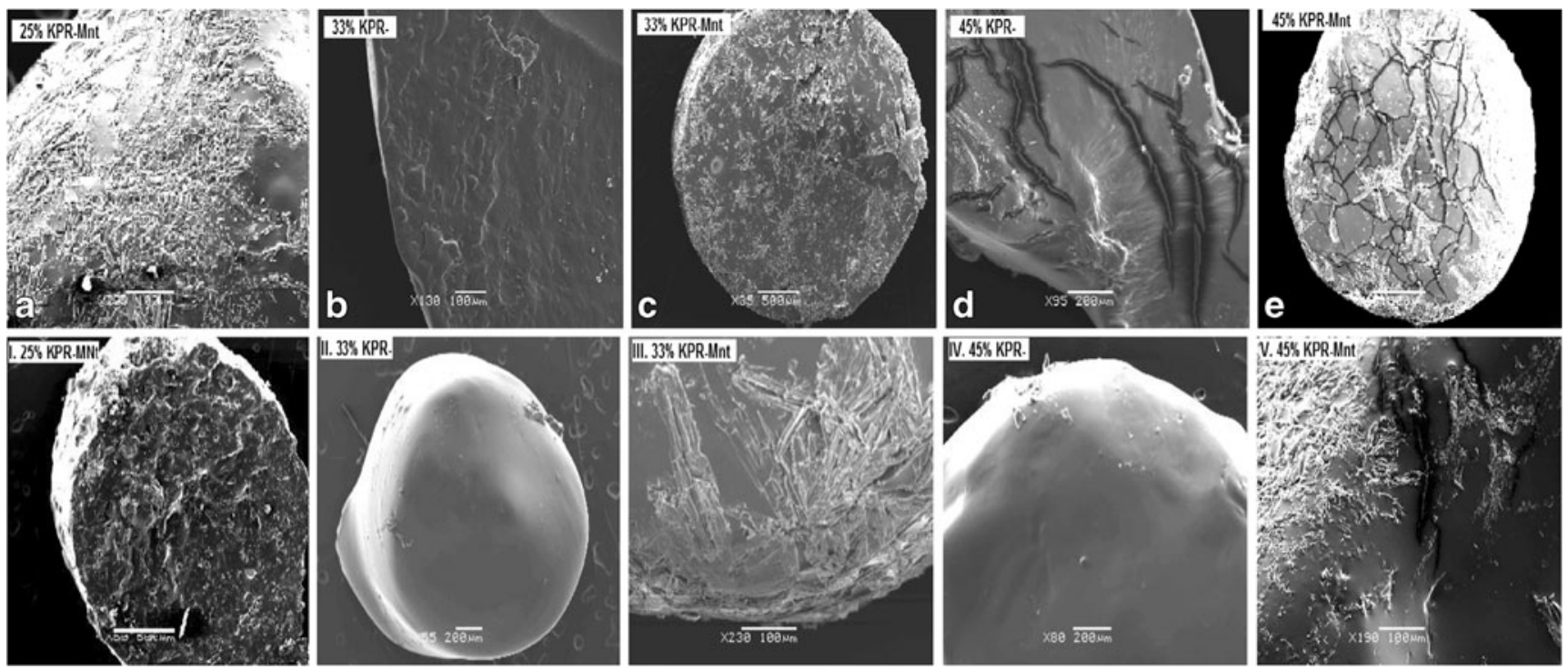

Fig. 3. SEM images of pellets manufactured using ELF polymer, (a-e) prior to dissolution and (I-V) post-exposure to dissolution media

employed maintained MNT in a crystalline state (confirmed by DSC studies), providing a necessary backbone for the pelletization and milling operations.

\section{Evaluation of Pellets}

DSC and mDSC studies performed on extruded pellets confirmed formation of a single-phase solid solution of KPR and EF/ELF. A single Tg and a crystalline peak for MNT were observed in the thermograms confirmed the physical state of component systems. Similar observations were made from polarized light microscope images of extruded systems.

\section{Scanning Electron Microscope}

Formulations comprising KPR and HPC exhibited a smooth surface suggesting a completely miscible single phase system. Formulations comprising MNT exhibited a similar smooth texture which was dispersed with crystalline mannitol. Figure 3a-e represents $\mathrm{H} 5, \mathrm{H} 3, \mathrm{H} 4, \mathrm{H} 7$, and $\mathrm{H} 8$, formulations, respectively. Extrudates representing higher drug loading formulations, $\mathrm{H} 7$ and $\mathrm{H} 8$, exhibited smooth surface which were interspersed with fissures. HPC is a long-chain, viscoelastic polymer that can expand or contract owing to flexibility of its polymer chains. A small molecule such as KPR lacks such viscoelastic characteristics and apparently might have resulted in unequal contraction, and hence development of fissures during cooling. It was also observed that during extrusion process these formulations exhibited decreased die swelling.

\section{In vitro Release Studies-Pellets}

Pellets manufactured utilizing ELF polymer exhibited faster drug release in comparison to EF pellets. A release of $52.7 \pm 0.6 \%$ and $74.5 \pm 1.6 \%$ in $1 \mathrm{~h}$ for $\mathrm{H} 1$ and $\mathrm{H} 3$ formulations, respectively, was observed. Formulations with mannitol as a pore former, $\mathrm{H} 2$ and $\mathrm{H} 4$, released $85.8 \pm 3.6 \%$ and $88.5 \pm 1.5 \%$ drug, respectively, (Table III). The extruded formulations, H2$\mathrm{H} 8$, had a comparatively faster release than an equivalent unextruded KPR (Fig. 4). H1 formulation comprising EF polymer did not exhibit a significant improvement over physical mixture blends $(p>0.05)$. However, addition of mannitol in $\mathrm{H} 2$ as well as $\mathrm{H} 4$ resulted in an improvement in release $(p<0.05)$.

HME process involves mixing of molten drug and polymers resulting in formation of a solid solution or dispersion of drug in a polymer matrix. Such dispersions or solutions, due to their inherent advantages, have been utilized to increase solubility of poorly soluble drugs (9). In our work, Klucel ${ }^{\mathrm{TM}}$ polymers were able to disperse amorphous KPR at a molecular level in a hydrophilic matrix. HPC enhances the dissolution process by increasing the wettability, surface area, and also aids in stabilization of amorphous KPR (44). Hydroxypropylcellulose polymers undergo dissolution via a swelling- and erosiondriven mechanism which is dependent upon chain length (45). Longer-chain polymers on swelling require a longer time to erode and hence result in slower release. Klucel ${ }^{\mathrm{TM}}$ ELF and EF polymers have a comparatively lower molecular weight and hence, undergo faster erosion, resulting in faster release of KPR. Observations made by Yuasa et al. who used different grades of HPC to control the release of a slightly poor soluble drug further support this inference $(45,46)$. Swelling and erosion of HPC occurs instantaneously, leading to rapid release of KPR. On comparing SEM images pellets pre- and post-dissolution, post-dissolution samples exhibited a rounded, smoother surface suggesting surface dissolution and a concurrent release of

Table III. Comparison of Release Profiles Using Similarity Factor Values-Effect of Drug Loading

\begin{tabular}{llll}
\hline ELF & \multicolumn{1}{c}{ H3 } & \multicolumn{1}{c}{ H5 } & \multicolumn{1}{c}{ H7 } \\
\hline \% Release in 1 h & $74.5 \pm 1.6$ & $75.50 \pm 1.1$ & $65.7 \pm 3.5$ \\
& H3-H5 & H3-H5 & H5-H7 \\
$f_{2}$ & 56 & 55 & 44 \\
ELF+MNT & $\mathrm{H} 4$ & $\mathrm{H} 6$ & $\mathrm{H} 8$ \\
\% Release in 1 h & $88.5 \pm 1.5$ & $68.3 \pm 4.0$ & $75.1 \pm 3.0$ \\
& $\mathrm{H} 4-\mathrm{H} 8$ & $\mathrm{H} 4-\mathrm{H} 6$ & $\mathrm{H} 4-\mathrm{H} 8$ \\
$f_{2}$ & 43 & 39 & 66 \\
\hline
\end{tabular}




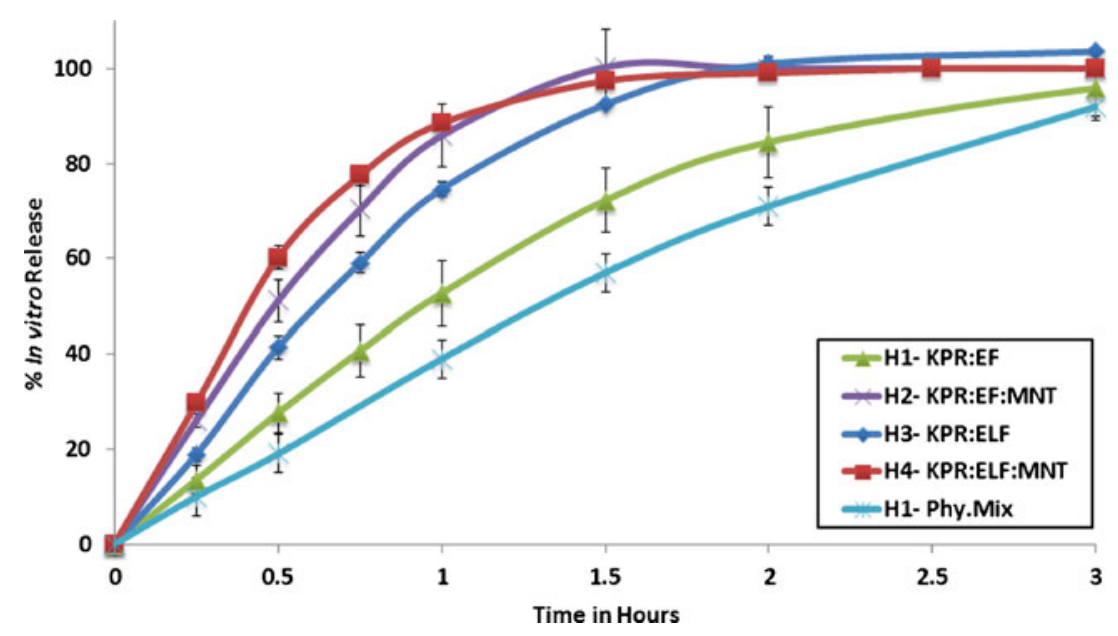

Fig. 4. In vitro release of pellets EF-ELF polymers

KPR (Fig. 3b (II, IV)). Enhancement of release with ELF polymers suggested that the release was carrier-dependent and hence can be altered, as required, by altering the molecular weight of the polymer utilized. Higher molecular weight grades of Klucel polymers have been utilized earlier in our lab to attain a similar carrier-dependent release (47). The factors-increased surface area, amorphous form, and a hydrophilic matrix-contribute towards an increase in dissolution rate. In addition, mannitol, due to its high solubility, solubilizes at a faster rate, creating micropores $(22,48)$ in the matrix, and enhances the release significantly $(p<0.05)$, (SEM images, Fig. 3b (I, III)). During HME process, molten polymer tends to densify on being pushed through a die, resulting in decreased porosity (49). MNT might have compensated for this decrease in porosity by forming micropores due to its high solubility and also reduced compressibility. Extrudates utilized were of $1 \mathrm{~mm}$ cross-section, significantly thicker, and might have resulted in a slower release in $\mathrm{H} 1$ formulation. Also, $\mathrm{EF}$ polymer exhibits slightly slower release which was offset by addition of MNT in $\mathrm{H} 2$ formulation.

Interest in hydrophilic polymer-based solid dispersions has gained interest over the last decades due to solubility related issues with conventional formulations. However, this technology comes with caveat that formulations that perform in vitro may fail in vivo. Carrier-mediated or drug-related phase conversion or precipitation can occur in super saturated conditions in these formulations. SDs rely on a hydrophilic polymer as a carrier material to increase wettability and an amorphous form to increase drug solubility in the media. It has been observed that such hydrophilic polymers solubilize at a faster rate leaving behind a super saturated drug in the media resulting in solution-mediated phase conversion (50). Sheen et al. observed that solid dispersion using melt technology did not result in increased bioavailability and suggested that this could be due to precipitation of the poorly soluble drug in gastric media (51). Dinunzio et al. observed that formulations which exhibited a slower release over a prolonged period of time resulted in better bioavailability by preventing supersaturation and recrystallization of itraconazole (13). Law et al. concluded the same that a slower release would benefit bioavailability as the precipitated crystalline form would require more media to undergo dissolution (12). Thus, a slower release, still in the domain of immediate release, might actually contribute towards increased bioavailability and better stability for SDs. Klucel polymers with a wide range of

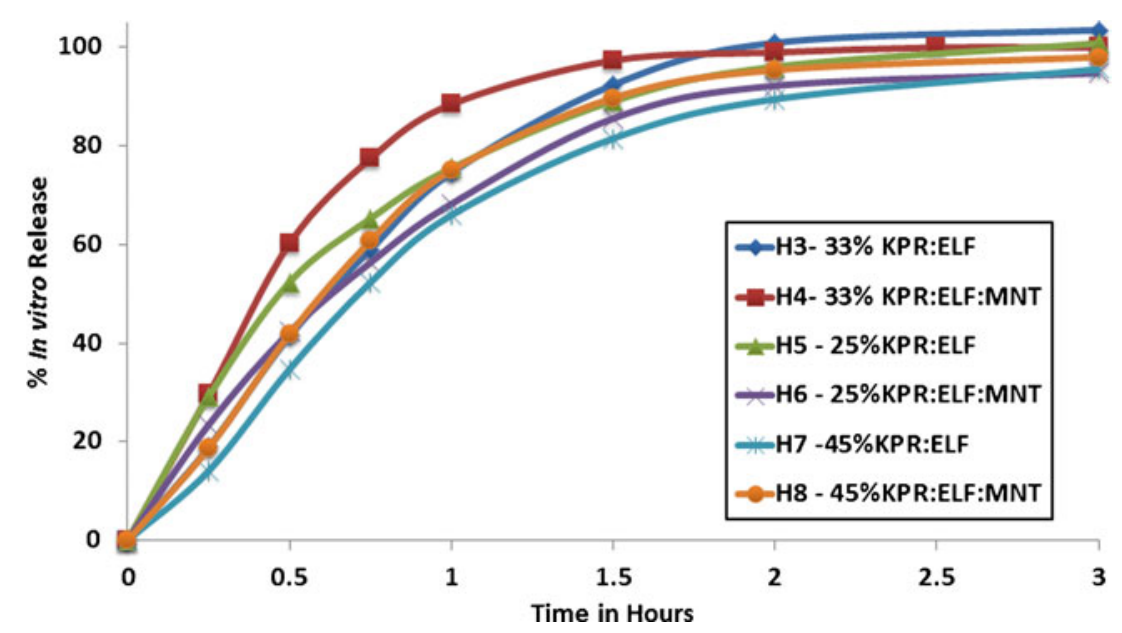

Fig. 5. In vitro release of pellets-effect of drug load on release 


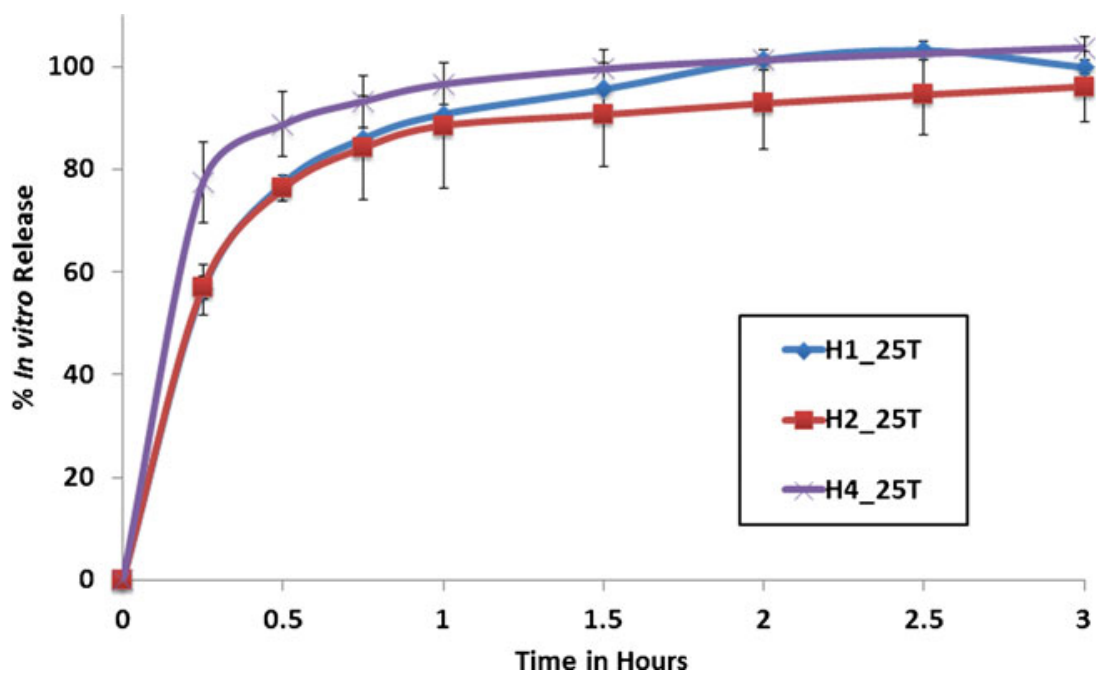

Fig. 6. In vitro release profiles tablets from extruded matrices

molecular weights can be appropriately selected to tailor such release.

\section{Effect of Drug Loading}

The dissolution profiles of pellets extruded at different drug load of $25 \%, 33 \%$, and $45 \%$ were compared (Fig. 5). Formulations $-\mathrm{H} 5$ and $\mathrm{H} 7$, with $25 \%$ and $45 \%$ KPR, respectively, had similar release profiles $\left(f_{2}>50\right)$ as H3 (33\% KPR) formulation (Table III). It was observed that an increase in KPR concentration decreased its release in $1 \mathrm{~h}$ from $74.5 \pm$ $1.6 \%$ to $65.7 \pm 3.5 \%$, for $\mathrm{H} 3$ and $\mathrm{H} 7$ formulations, respectively. A similar trend was observed with mannitol and ELF formulations $\mathrm{H} 4, \mathrm{H} 6$, and $\mathrm{H} 8$. $\mathrm{H} 4$ formulation with an equal distribution of KPR, ELF, and MNT (1:1:1) released the drug in the least amount of time. In all the formulations studied, pellets manufactured utilizing ELF exhibited a faster release but at higher drug loading of $45 \%$; no significant improvement in the release of KPR was observed (similar profiles as per $f_{2}$ ).

As per Higuchi matrix model, release from a matrix occurs by dissolution and diffusion of one component through the other (52). Due to difference in solubility, component with higher solubility solubilizes at a faster rate, leaving behind component with comparatively lesser solubility (53). At higher drug loading (45\%), less soluble KPR forms infinite or continuous clusters, thereby restricting diffusion of media, preventing surface penetration, and hence solubilization. This can also be attributed to an increased tortuosity and decreased diffusivity (54) caused by component systems. In formulations such as H4, infinite clusters or continuous phases are formed by soluble excipients (HPC and MNT), thereby decreasing tortuosity and increasing diffusivity of the dissolution media. A similar decrease in release has been observed in extruded matrices by Crowley et al. and Zhang et al. $(55,56)$. An increase in drug loading resulted in a decreased release and a drop in bioavailability for ritonavir-based solid dispersions. This drop in release was attributed to a localized phase conversion of amorphous RTR to a crystalline form (12). KPR exhibited miscibility of approximately $60 \%$ in DSC studies without undergoing any recrystallization on cooling. We assume that there might be a localized recrystallization of KPR on contact with the dissolution media, thus, slowing down release. Hence, this phase conversion, if any, can be considered to be solution-mediated and not carrier-mediated. This conversion is a drug-related attribute and beyond the scope of this research work.

SEM was utilized to evaluate morphological changes occurring in pellets exposed to disso media. SEM images of H5 (25\% KPR) pellets exhibited a significant change in morphology on dissolution which can be attributed to soluble ELF and MNT (Fig. 3b-i). The dented appearance was formed due to rapid solubilization of hydrophilic excipients by an inwardmoving solvent front. The soluble polymers formed channels allowing media to enter the matrix.

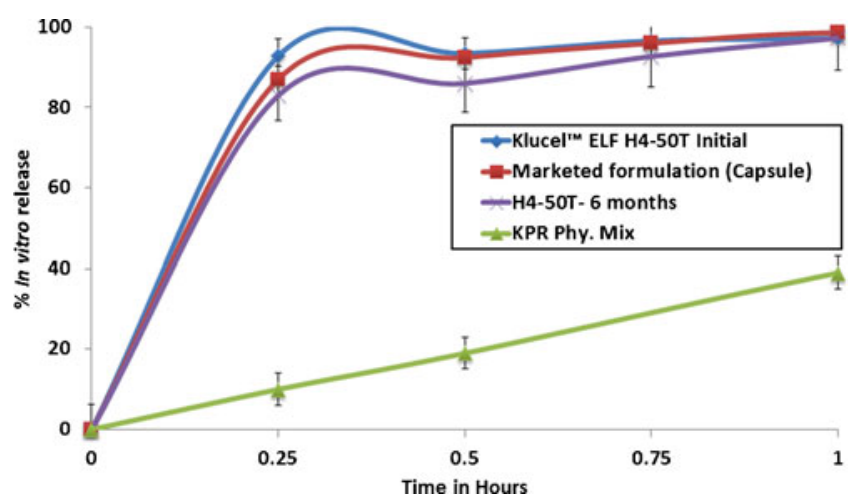

Fig. 7. In vitro release comparison to marketed capsule 


\section{In vitro Release Studies-Tablets}

HME exerts compression on molten material that results in densification and a subsequent decrease in porosity. This densification leads to a delayed disintegration and also decreased surface area. These problems can very well be addressed by milling the material and addition of super disintegrant to disperse the material. Extrudates were milled and compressed with the addition of MCC as a direct compression vehicle, and AcDisol aided disintegration. The release profiles exhibited a similar rank order as was observed for the pellets (Fig. 6). Tablets manufactured from H4 matrices exhibited rapid release in comparison to rest of the formulations. H3$25 \mathrm{~T}$ showed a slower release when compared with other tablet formulations. ELF polymer, being more plastic, forms a denser compact on being compressed, thus slowing down the release due to decreased porosity (24). This increased compactibility also resulted in increased tensile strength and has been further detailed in the tablet characterization section.

Tablets were compressed to a 50-mg strength utilizing 11$\mathrm{mm}$ round biconcave punch at a tablet weight of $400 \mathrm{mg}$ using $\mathrm{H} 4$ matrices. The percentage drug release in 15 min was $92.8 \pm$ $4.4 \%$ and $87.0 \pm 1.3 \%$, respectively, for $\mathrm{H} 4-50 \mathrm{~T}$ and marketed formulation. We were able to successfully utilize extrusion process to manufacture immediate release tablet formulations of KPR utilizing Klucel polymers. The milled matrices utilized in tablet formulations exhibited faster release in comparison to pellets due to particle size reduction of extrudates which not only increases the surface area for dissolution but also decreases the potential for formation of a release controlling swellable polymer matrix. The dissolution profiles are presented in Fig. 7.

\section{Compactibility Profiles}

Another advantage of using HME is the physical transformation of drug and excipients which influences tabletting behavior. Compressibility, Compactibility, and Tabletability profiles as described by Tye et al. were utilized to understand the effect of melt extrusion on tabletting (35).

Compressibility profiles did not exhibit any difference among extruded formulations. However, extruded blends were found to be more compressible compared with un-extruded formulations. The increased ability to form compacts can be attributed to increased plasticity of the extruded material (20). The extruded systems had an almost similar

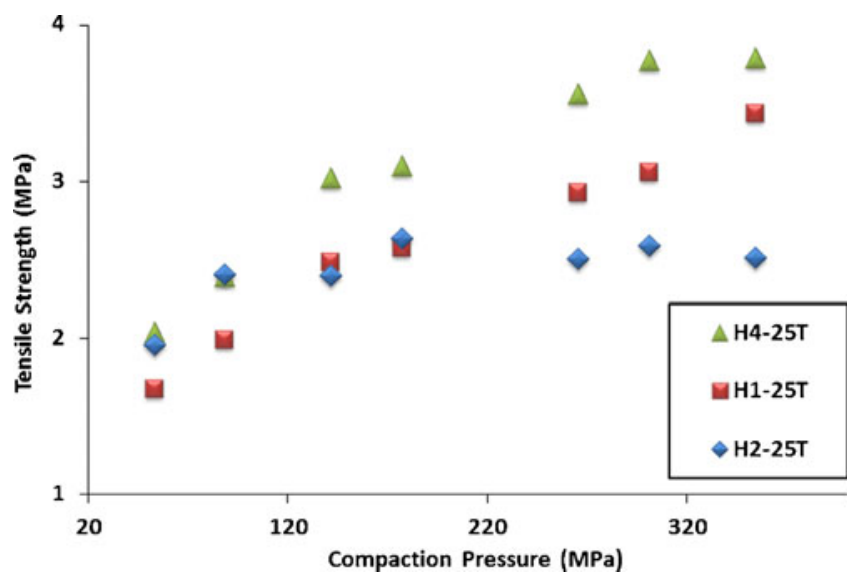

Fig. 8. Tabletability profiles

tabletting property to un-extruded blends. Among all the formulations, H4-25T exhibited the better compactibility and tabletability (Fig. 8). H3-25T tablets were plastic in nature, and hence profiles could not be generated.

With a decrease in molecular weight of HPC, compactibility and plasticity increase with a consequential decrease in elasticity (24). Smaller-chain-length ELF polymer hence exhibits less elastic recovery and higher plasticity and undergoes a greater deformation, forming better compacts on being compressed. Also, HME converts the drug and HPC to an amorphous form, leading to a subsequent increase in surface area for bonding between the tabletting excipients (20). This transformation could be a reason for increased tabletting properties of extruded systems. Also, the smaller chains in ELF might have contributed towards a lesser elastic recovery, and hence, no capping was observed at higher compaction pressures for un-extruded tablets T3-25T andT4-25T. T3 and T4 tablets were compressed from un-extruded mixtures with blend compositions similar to $\mathrm{H} 3$ and $\mathrm{H} 4$ tablets.

Conventional hardness testing was performed on tablets compressed at same compaction pressure on a tableting press. H1-25T, H2-25T, H3-25T, and H4-25T exhibited hardness values of $99.8 \pm 7.7,79.9 \pm 3.0,108.6 \pm 2.6$, and $88.5 \pm 5.5 \mathrm{~N}$, respectively (Fig. 9). Addition of mannitol resulted in a decrease in hardness values. Mannitol, a crystalline excipient, on compression, undergoes plastic deformation whereas HPC has a viscoelastic character that aids in holding the matrix together. A similar behavior was observed in HME extruded matrices, with Klucel ${ }^{\mathrm{TM}}$ ELF having better performance than EF.

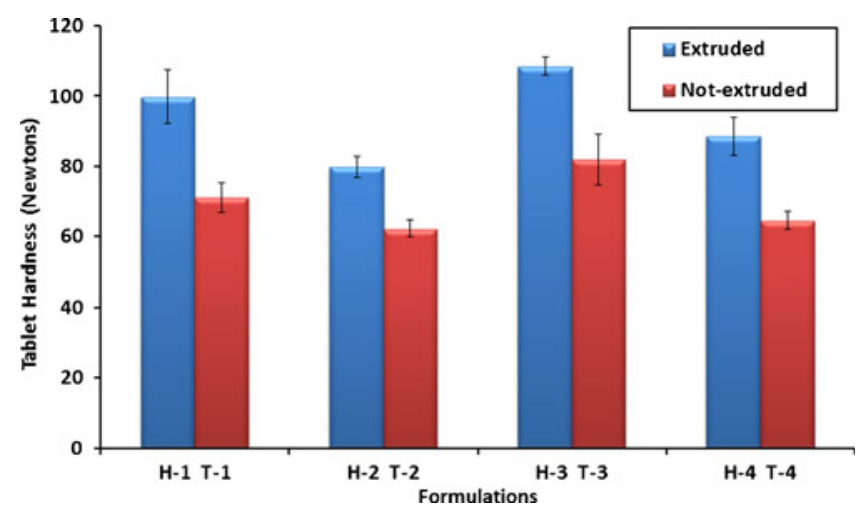

Fig. 9. Tablet hardness evaluation-Extruded Vs Not-Extruded formulations 


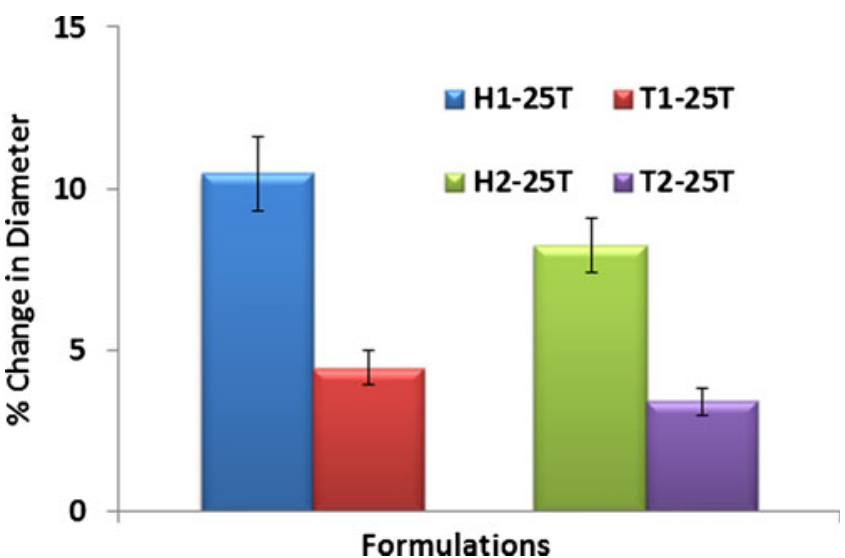

Fig. 10. Tablet hardness evaluation-texture analyzer

\section{Hardness Evaluation Utilizing Texture Analyzer}

The classical hardness testing registers force required for a tablet to fail (break) under applied diametrical force between two anvils. The test fails to register the dynamics at point of failure, and hence, a texture analyzer was utilized to analyze the process of a tabletting breaking. The area of the plot (force to distance travelled) can be utilized to calculate the work of failure $\left(W_{\mathrm{f}}\right)$ which is the work done for diametrical breaking of tablet. The peak of the plot can be used to calculate the distance travelled by the probe at the point of contact to the distance from the tablet surface to cause it to break.

Tablets manufactured from extruded matrices were more resistant to breaking in comparison to un-extruded tablets. The extent of deformation as measured by the percentage change in diameter of the tablet at failure (breaking) was higher for extruded tablets (Fig. 10). Among the extruded tablets, $W_{\mathrm{f}}$ was higher for extruded tablets. These observations correlated with the data generated from compaction profiles.

\section{Stability Testing}

Physico-chemical analysis was performed on pellets that were stored at room and accelerated stability conditions for a period of 6 months. Increased temperatures and presence of moisture enhances recrystallization and also degradation of drugs. mDSC studies and DSC studies confirmed the presence of an amorphous form of the drug based on the glass transition temperatures $(\mathrm{Tg})$ and lack of crystalline melting peaks. Stabilization of amorphous forms can be achieved by forming solid solutions that either prevent molecular mobility by forming glassy solutions, or stabilize it by molecular interactions, such as hydrogen bonding between the component systems. Thermodynamic stability in solid solutions by HME that have low Tg values has been reported due to formation of a homogenously dispersed matrix and formation of hydrogen bonds between the drug and polymer $(57,58)$. In our studies, KPR/ HPC were found to form a miscible system till a $60 \%$ drug loading though only a $33 \%$ loading was utilized to form pellets. Stability of such a system can be attributed to increased solid state solubility and hydrogen bond forming tendency of HPC (59). All the extruded pellets were found to be stable for a period of 6 months at the storage conditions tested. The percent drug remaining at the end of last time point was more than $95 \%$ after 6 months of storage at $40^{\circ} \mathrm{C} / 75 \% \mathrm{RH}$; however, assay for related substances such as degradants was not performed as KPR was only used a model drug.

The crystallinity was evaluated utilizing XRD and DSC studies. KPR remained in an amorphous form in XRD and DSC spectra. Crystalline peaks of KPR at $2 \theta$ values corresponding to $14.2,18.4$, and $22.9(19,29)$ were absent in tablet mixtures at the end of storage time points (Fig. 11). Tablets stored at $40^{\circ} \mathrm{C} / 75 \% \mathrm{RH}$ showed slower release compared with initial release profiles $\left(f_{2}<50\right)$. H4-50T Tablets stored at $25^{\circ} \mathrm{C} / 60 \% \mathrm{RH}$ had similar profiles to their initial release (Fig. 7). The difference could be attributed to absorption of moisture onto tablets that affected the disintegration time and hence a slower release at high humidity conditions. Change in packaging or use of

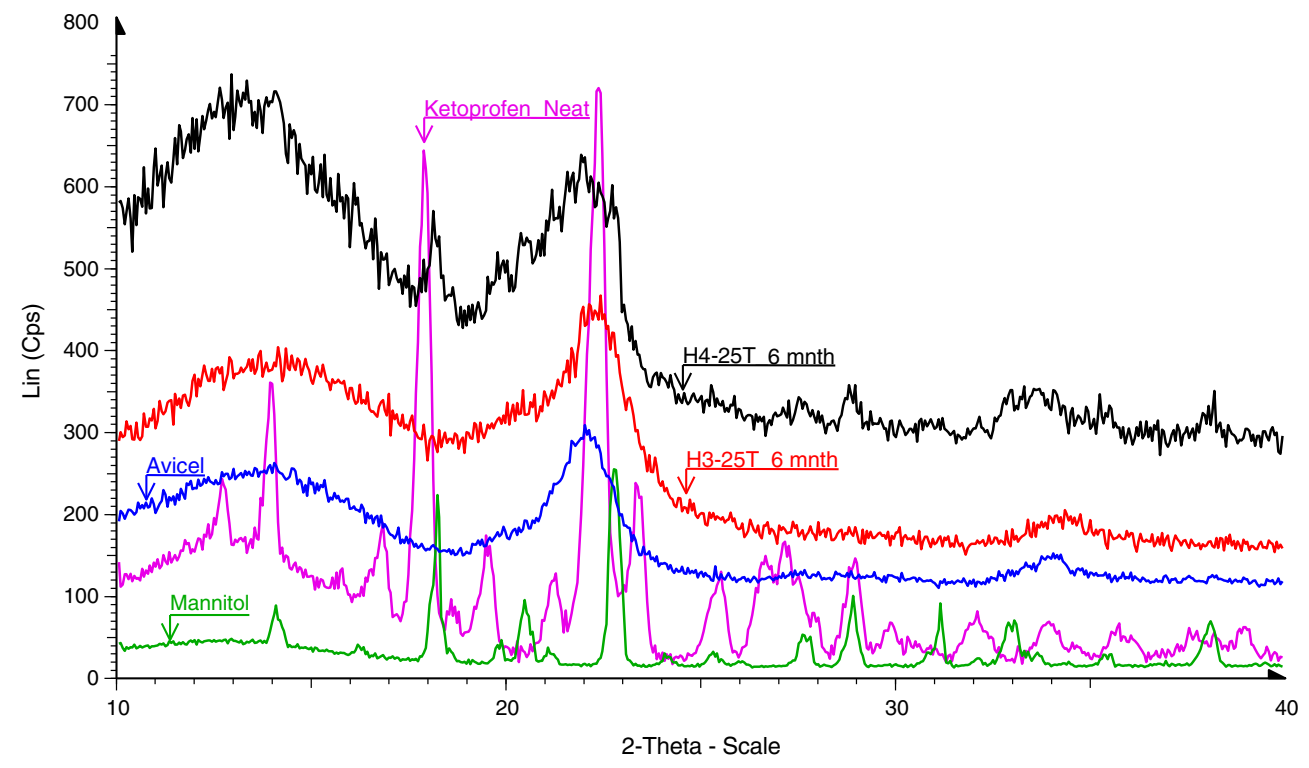

Fig. 11. XRD images of H4-25T tablets, 6 months storage time point 
desiccant might help in overcoming these factors. Optimized H4$50 \mathrm{~T}$ formulation stored at $25^{\circ} \mathrm{C} / 60 \% \mathrm{RH}$ at the end of 6 months had a similar profile $\left(f_{2}>50\right)$.

\section{CONCLUSION}

Klucel $^{\mathrm{TM}}$ hydroxypropylcellulose polymers were successfully utilized as HME matrix formers and solubility-enhancing agents. Drug and polymer were found to be miscible with each other even at high drug loading, suggesting solid-state solubilization of KPR in HPC. Release was dependent upon the molecular weight of the polymer used, with Klucel ELF exhibiting a faster release than EF. HPC polymers with wide range of molecular weights can be used to tailor release profiles that can address some of the disadvantages associated with solid dispersions. HME process also aided in enhancing tabletting properties and imparted a plastic character to tablets. An optimized tablet formulation exhibited similar release to a marketed formulation. Physical stability evaluation performed using XRD and DSC studies confirmed physical stability of the model drug, suggesting applicability of HPC in stabilizing amorphous forms by forming solid solutions.

\section{ACKNOWLEDGMENTS}

We would like to thank Mr. George W. Gereg of Boehringer Ingelheim Pharmaceuticals for the generous loan of tabletting punches and fixture used in compactibility studies.

\section{REFERENCES}

1. Leuner C, Dressman J. Improving drug solubility for oral delivery using solid dispersions. Eur J Pharm Biopharm. 2000;50(1):47-60.

2. Marin MT, Margarit MV, Salcedo GE. Characterization and solubility study of solid dispersions of flunarizine and polyvinylpyrrolidone. Farmaco. 2002;57(9):723-7.

3. Ye G, Wang S, Heng PWS, Chen L, Wang C. Development and optimization of solid dispersion containing pellets of itraconazole prepared by high shear pelletization. Int J Pharm. 2007;337(12):80-7.

4. DiNunzio JC, Brough C, Hughey JR, Miller DA, Williams Iii RO, McGinity JW. Fusion production of solid dispersions containing a heat-sensitive active ingredient by hot melt extrusion and Kinetisol® dispersing. Eur J Pharm Biopharm. 2010;74(2):340-51.

5. Martins RM, Siqueira S, Tacon LA, Freitas LAP. Microstructured ternary solid dispersions to improve carbamazepine solubility. Powder Technol. 2012;215-216(0):156-65.

6. Albers J, Alles R, Matthée K, Knop K, Nahrup JS, Kleinebudde P. Mechanism of drug release from polymethacrylate-based extrudates and milled strands prepared by hot-melt extrusion. Eur J Pharm Biopharm. 2009;71(2):387-94.

7. Jijun F, Lili Z, Tingting G, Xing T, Haibing H. Stable nimodipine tablets with high bioavailability containing NM-SD prepared by hot-melt extrusion. Powder Technol. 2010;204(2-3):214-21.

8. Repka MA, Battu SK, Upadhye SB, Thumma S, Crowley MM, Zhang F, et al. Pharmaceutical applications of hot-melt extrusion: part II. Drug development and industrial pharmacy. Res Support, N I H, Extramural Rev. 2007;33(10):1043-57.

9. Serajuddin AT. Solid dispersion of poorly water-soluble drugs: early promises, subsequent problems, and recent breakthroughs. J Pharm Sci. 1999;88(10):1058-66.

10. Vasconcelos T, Sarmento B, Costa P. Solid dispersions as strategy to improve oral bioavailability of poor water soluble drugs. Drug Discov Today [Rev]. 2007;12(23-24):1068-75.

11. Van Speybroeck M, Mols R, Mellaerts R, Thi TD, Martens JA, Van Humbeeck $\mathrm{J}$, et al. Combined use of ordered mesoporous silica and precipitation inhibitors for improved oral absorption of the poorly soluble weak base itraconazole. Eur J Pharm Biopharm: J Arbeitsgemeinschaft fur Pharmazeutische Verfahrenstechnik eV (Res Support, non-U S gov't). 2010;75(3):354-65.

12. Law D, Schmitt EA, Marsh KC, Everitt EA, Wang W, Fort JJ, et al. Ritonavir-PEG 8000 amorphous solid dispersions: in vitro and in vivo evaluations. J Pharm Sci. 2004;93(3):563-70.

13. DiNunzio JC, Miller DA, Yang W, McGinity JW, Williams 3rd RO. Amorphous compositions using concentration enhancing polymers for improved bioavailability of itraconazole. Mol Pharm. 2008;5(6):968-80.

14. Repka MA, Shah S, Lu J, Maddineni S, Morott J, Patwardhan K, et al. Melt extrusion: process to product. Expert Opin Drug Deliv. 2012;9(1):105-25.

15. Breitenbach J. Melt extrusion: from process to drug delivery technology. Eur J Pharm Biopharm. 2002;54(2):107-17.

16. Thommes M, Baert L, Rosier J. $800 \mathrm{mg}$ darunavir tablets prepared by hot melt extrusion. Pharm Dev Technol. 2010; 16:645650, Aug 23.

17. Prodduturi S, Urman KL, Otaigbe JU, Repka MA. Stabilization of hot-melt extrusion formulations containing solid solutions using polymer blends. AAPS PharmSciTech [Res Support, N I H, Extramural]. 2007;8(2):Article 50.

18. Andrews GP, AbuDiak OA, Jones DS. Physicochemical characterization of hot melt extruded bicalutamide-polyvinylpyrrolidone solid dispersions. J Pharmaceut Sci [Comp Stud]. 2010;99(3):1322-35.

19. Crowley MM, Fredersdorf A, Schroeder B, Kucera S, Prodduturi $\mathrm{S}$, Repka MA, et al. The influence of guaifenesin and ketoprofen on the properties of hot-melt extruded polyethylene oxide films. Eur J Pharm Sci. 2004;22(5):409-18.

20. Ndindayino F, Henrist D, Kiekens F, Van den Mooter G, Vervaet C, Remon JP. Direct compression properties of melt-extruded isomalt. Int J Pharm. 2002;235(1-2):149-57.

21. Lopes Jesus AJ, Nunes SC, Ramos Silva M, Matos Beja A, Redinha JS. Erythritol: crystal growth from the melt. Int J Pharm. 2010;388(1-2):129-35.

22. Zajc N, Obreza A, Bele M, Srcic S. Physical properties and dissolution behaviour of nifedipine/mannitol solid dispersions prepared by hot melt method. Int J Pharm. 2005;291(1-2):518.

23. Repka MA, Gutta K, Prodduturi S, Munjal M, Stodghill SP. Characterization of cellulosic hot-melt extruded films containing lidocaine. Eur J Pharm Biopharm. 2005;59(1):189-96.

24. Picker-Freyer KM, Durig T. Physical mechanical and tablet formation properties of hydroxypropylcellulose: in pure form and in mixtures. AAPS PharmSciTech. 2007;8(4):E92.

25. Onoue S, Sato H, Ogawa K, Kawabata Y, Mizumoto T, Yuminoki $\mathrm{K}$, et al. Improved dissolution and pharmacokinetic behavior of cyclosporine A using high-energy amorphous solid dispersion approach. Int J Pharm. 2010;399(1-2):94-101.

26. Ishizaki T, Sasaki T, Suganuma T, Horai Y, Chiba K, Watanabe $\mathrm{M}$, et al. Pharmacokinetics of ketoprofen following single oral, intramuscular and rectal doses and after repeated oral administration. Eur J Clin Pharmacol. 1980;18(5):407-14.

27. Kheradmandnia S, Vasheghani-Farahani E, Nosrati M, Atyabi F. Preparation and characterization of ketoprofen-loaded solid lipid nanoparticles made from beeswax and carnauba wax. Nanomedicine. 2010;6(6):753-9.

28. Jachowicz R, Nurnberg E, Pieszczek B, Kluczykowska B, Maciejewska A. Solid dispersion of ketoprofen in pellets. Int J Pharm. 2000;206(1-2):13-21.

29. Fukuda M, Miller DA, Peppas NA, McGinity JW. Influence of sulfobutyl ether beta-cyclodextrin (Captisol) on the dissolution properties of a poorly soluble drug from extrudates prepared by hot-melt extrusion. Int J Pharm. 2008;350(1-2):188-96.

30. Araya H, Tomita M, Hayashi M. The novel formulation design of self-emulsifying drug delivery systems (SEDDS) type O/W microemulsion III: the permeation mechanism of a poorly water soluble drug entrapped $\mathrm{O} / \mathrm{W}$ microemulsion in rat isolated intestinal membrane by the Ussing chamber method. Drug Metab Pharmacokinet. 2006;21(1):45-53.

31. Ahmed IS, Fatahalla FA. Pilot study of relative bioavailability of two oral formulations of ketoprofen $25 \mathrm{mg}$ in healthy subjects. A fast-dissolving lyophilized tablet as compared to immediate release tablet. Drug Dev Ind Pharm. 2007;33(5):505-11. 
32. Ahmed IS, Nafadi MM, Fatahalla FA. Formulation of a fastdissolving ketoprofen tablet using freeze-drying in blisters technique. Drug Dev Ind Pharm. 2006;32(4):437-42.

33. Crowley MM, Zhang F, Repka MA, Thumma S, Upadhye SB, Battu SK, et al. Pharmaceutical applications of hot-melt extrusion: part I. Drug development and industrial pharmacy. Res Support, N I H, Extramural Rev. 2007;33(9):909-26.

34. Sun C, Grant DJ. Compaction properties of L-lysine salts. Pharm Res. 2001;18(3):281-6.

35. Tye CK, Sun CC, Amidon GE. Evaluation of the effects of tableting speed on the relationships between compaction pressure, tablet tensile strength, and tablet solid fraction. J Pharm Sci. 2005;94(3):465-72.

36. Lakshman JP, Cao Y, Kowalski J, Serajuddin AT. Application of melt extrusion in the development of a physically and chemically stable high-energy amorphous solid dispersion of a poorly watersoluble drug. Mol Pharm. 2008 Oct 7.

37. Lakshman JP, Cao Y, Kowalski J, Serajuddin AT. Application of melt extrusion in the development of a physically and chemically stable high-energy amorphous solid dispersion of a poorly watersoluble drug. Mol Pharm. 2008;5(6):994-1002.

38. Palmieri GF, Cantalamessa F, Di Martino P, Nasuti C, Martelli S. Lonidamine solid dispersions: in vitro and in vivo evaluation. Drug Dev Ind Pharm. 2002;28(10):1241-50.

39. Kanaujia P, Lau G, Ng WK, Widjaja E, Schreyer M, Hanefeld A, et al. Investigating the effect of moisture protection on solid-state stability and dissolution of fenofibrate and ketoconazole solid dispersions using PXRD, HSDSC and Raman microscopy. Drug Development and Industrial Pharmacy. 2011;Mar 21.

40. Mididoddi PK, Repka MA. Characterization of hot-melt extruded drug delivery systems for onychomycosis. Eur J Pharm Biopharm. 2007;66(1):95-105.

41. Janssens S, de Armas HN, Remon JP, Van den Mooter G. The use of a new hydrophilic polymer, Kollicoat IR $®$, in the formulation of solid dispersions of Itraconazole. Eur J Pharm Sci. 2007;30(3-4):288-94.

42. Pinto E, Yang H, Sosnowik AJ, Harcum WW, Durig T. Melt flow properties of hydroxypropyl cellulose for solubilization of lipophilic actives. American Association of Pharmaceutical Scientists Annual Meeting and Exposition. Los Angeles Convention Centre, CA 2009.

43. Repka MA, Gerding TG, Repka SL, McGinity JW. Influence of plasticizers and drugs on the physical-mechanical properties of hydroxypropylcellulose films prepared by hot melt extrusion. Drug Dev Ind Pharm. 1999;25(5):625-33.

44. He H, Yang R, Tang X. In vitro and in vivo evaluation of fenofibrate solid dispersion prepared by hot-melt extrusion. Drug Development and Industrial Pharmacy. In Vitro Randomized Controlled Trial. 2010;36(6):681-7.

45. Yuasa H, Ozeki T, Kanaya Y, Oishi K. Application of the solid dispersion method to the controlled release of medicine. IV. Precise control of the release rate of a water soluble medicine by using the solid dispersion method applying the difference in the molecular weight of a polymer. Chem Pharm Bull (Tokyo). 1993;41(5):933-6.
46. Yuasa H, Takahashi H, Ozeki T, Kanaya Y, Ueno M. Application of the solid dispersion method to the controlled release of medicine. III. Control of the release of slightly water soluble medicine from solid dispersion granules. Chem Pharm Bull (Tokyo). 1993;41(2):397-9.

47. Prodduturi S, Manek RV, Kolling WM, Stodghill SP, Repka MA. Water vapor sorption of hot-melt extruded hydroxypropyl cellulose films: effect on physico-mechanical properties, release characteristics, and stability. J Pharm Sci. 2004;93(12):3047-56.

48. Arias MJ, Gines JM, Moyano JR, Perez-Martinez JI, Raasco AM. Influence of the preparation method of solid dispersions on their dissolution rate: study of triamterene-d-mannitol system. Int J Pharm. 1995;123:25-31.

49. Andrews GP, Abu-Diak O, Kusmanto F, Hornsby P, Hui Z, Jones DS. Physicochemical characterization and drug-release properties of celecoxib hot-melt extruded glass solutions. J Pharm Pharmacol. 2010;62(11):1580-90.

50. Kim J-S, Kim M-S, Park HJ, Jin S-J, Lee S, Hwang S-J. Physicochemical properties and oral bioavailability of amorphous atorvastatin hemi-calcium using spray-drying and SAS process. Int J Pharm. 2008;359(1-2):211-9.

51. Sheen P-C, Khetarpal VK, Cariola CM, Rowlings CE. Formulation studies of a poorly water-soluble drug in solid dispersions to improve bioavailability. Int J Pharm. 1995;118(2):221-7.

52. Higuchi T. Mechanism of sustained-action medication. Theoretical analysis of rate of release of solid drugs dispersed in solid matrices. J Pharm Sci. 1963;52:1145-9.

53. Craig DQ. The mechanisms of drug release from solid dispersions in water-soluble polymers. Int J Pharm. 2002;231(2):131-44.

54. Leuenberger H, Rohera BD, Haas C. Percolation theory-a novel approach to solid dosage form design. Int J Pharm. 1987;38(1-3):109-15.

55. Crowley MM, Schroeder B, Fredersdorf A, Obara S, Talarico M, Kucera S, et al. Physicochemical properties and mechanism of drug release from ethyl cellulose matrix tablets prepared by direct compression and hot-melt extrusion. Int $\mathrm{J}$ Pharmaceut [Res Support, Non-U S Gov't]. 2004;269(2):509-22.

56. Zhang F, McGinity JW. Properties of hot-melt extruded theophylline tablets containing poly (vinyl acetate). Drug Dev Ind Pharm. 2000;26(9):931-42.

57. Qian F, Huang J, Hussain MA. Drug-polymer solubility and miscibility: stability consideration and practical challenges in amorphous solid dispersion development. J Pharm Sci. 2010;99 (7):2941-7.

58. Vasanthavada M, Tong WQ, Joshi Y, Kislalioglu MS. Phase behavior of amorphous molecular dispersions II: role of hydrogen bonding in solid solubility and phase separation kinetics. Pharm Res. 2005;22(3):440-8.

59. Ozeki T, Yuasa H, Kanaya Y. Application of the solid dispersion method to the controlled release of medicine. IX. Difference in the release of flurbiprofen from solid dispersions with poly (ethylene oxide) and hydroxypropylcellulose and the interaction between medicine and polymers. Int J Pharm. 1997;155(2):209-17. 